\title{
Clinical insights into appropriate choice of antimicrobials for acute respiratory tract infections
}

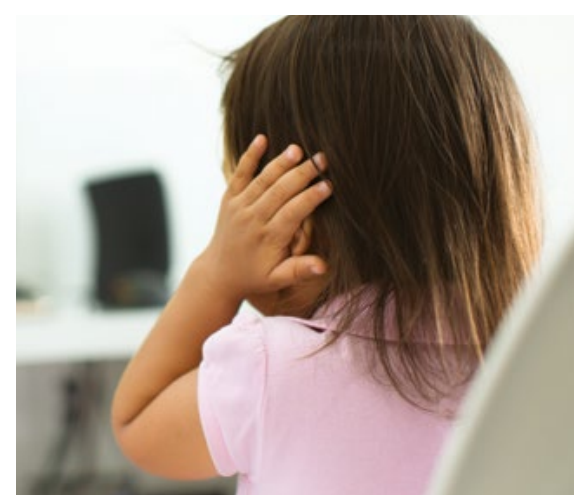

CPD

Tim Monaghan, Ruby Biezen,

Kirsty Buising, Christine Hallinan,

Ron Cheah, Jo-Anne Manski-Nankervis

\section{Background and objective}

Australia has relatively high rates of antibiotic prescribing in the community. The aim of this study was to identify clinical insights regarding antibiotic prescribing choices for the management of common upper respiratory tract infections through analysis of anonymised primary care electronic medical records (EMRs).

\section{Methods}

EMR data relating to 1926 antimicrobial prescriptions for tonsillitis, pharyngitis and acute rhinosinusitis in adults and acute otitis media (AOM) in children were extracted from 11 general practices in Victoria and analysed for consistency with Australian Therapeutic Guidelines recommendations.

\section{Results}

The analysis suggests that underdosing of amoxicillin for $\mathrm{AOM}$ in children, prescription of phenoxymethylpenicillin at doses not consistent with Therapeutic Guidelines recommendations for tonsillitis and pharyngitis in adults, and potential overprescription of antibiotics for patients with acute rhinosinusitis are not infrequent in general practice.

\section{Discussion}

Anonymised EMR data provide an opportunity to analyse antibiotic prescribing practices at scale and provide insights relevant to clinical practice.
INAPPROPRIATE ANTIMICROBIAL PRESCRIBING contributes not only to the growing antimicrobial resistance crisis, but also to potential adverse outcomes such as allergic reactions ${ }^{1}$ and drug-drug interactions. ${ }^{2}$ Despite a recent downtrend in community antimicrobial prescribing in Australia, ${ }^{3}$ rates of prescribing per capita remain high when compared with other Organisation for Economic Co-operation and Development (OECD) nations. This is particularly an issue for upper respiratory tract infections (URTIs), which have higher rates of prescribing than would be expected according to local guidelines. ${ }^{4}$ Further, improving the appropriateness of antimicrobial prescribing by general practitioners (GPs) for URTIs has been targeted as a key 'area for action' in the latest report on antimicrobial use and resistance in human health by the Australian Commission on Safety and Quality in Health Care. ${ }^{5}$ As the health professionals who prescribe the majority of antimicrobials in Australia, ${ }^{4}$ GPs have a key role in optimising antimicrobial use. It is, therefore, critically important for GPs to make appropriate choices when prescribing antibiotics for common respiratory tract infections such as acute otitis media (AOM), tonsillitis and pharyngitis, and acute rhinosinusitis.

To design targeted quality improvement programs to assist GPs to optimise their antimicrobial prescribing, it is imperative to understand current prescribing practices. Pharmaceutical Benefits Scheme (PBS) data, the traditional source of information on community antimicrobial prescribing, ${ }^{4}$ cannot provide insights into why antimicrobials are prescribed or whether the choice of antimicrobial prescribed is appropriate. Primary care data can provide these insights.

Anonymised electronic medical record (EMR) data are increasingly being extracted from general practices and collated into large data repositories such as MedicineInsight managed by NPS MedicineWise, ${ }^{6}$ the University of Melbourne's Patron repository, ${ }^{7}$ Outcome Health's Population Level Analysis and Reporting tool ${ }^{8}$ and the planned National Primary Health Care Data Asset. ${ }^{9}$ Algorithms can analyse large sets of EMR data to gain insights into antimicrobial prescribing 
practices in primary care with a specificity previously not possible at such scale. The aim of this study was to identify clinical insights regarding antibiotic prescribing choices for the management of AOM in children, tonsillitis and pharyngitis in adults and acute rhinosinusitis in adults through analysis of anonymised primary care EMR data.

\section{Methods}

EMR data relating to 19,742 antimicrobial prescriptions were extracted from 11 general practices in Victoria who participated in the early stages of the development of the University of Melbourne's Patron ${ }^{7}$ primary care data repository between 1 July 2017 and 30 June 2018. The extracted EMR data used in the analysis included the practice ID, patient ID, visit date, age at visit, patient gender, weight (recorded within six months of the visit date), indication for prescription, reason for visit and prescribed antimicrobial type, route, strength, dose, frequency and quantity (including repeat prescriptions). Extracted EMR data did not include consultation notes, prescription instructions inputted as 'free text' or pregnancy status, nor did it include identifying information such as patient name, address or date of birth. Paediatric patients were defined as those with an 'age at visit' of 12 years or less for the purposes of analysing paediatric weight-based dosing.

Of the 19,742 antimicrobial prescriptions extracted, 1926 were included for analysis on the basis of a 'reason for visit' or 'reason for prescription' that corresponded to one of the three indications studied: tonsillitis and pharyngitis in adults, AOM in children or acute rhinosinusitis in adults. Clinicians frequently used 'free text' when recording a 'reason for visit' or 'reason for prescription' into the EMRs, rather than coded diagnoses, resulting in multiple variations on how each indication was recorded in the EMRs. Therefore, clinical discretion was used to determine a set of terms for 'reason for prescription' and 'reason for visit' that corresponded to each indication.
An algorithm was created in Stata/IC Version 15.0 software to analyse EMR data for each of the 1926 prescriptions extracted to determine consistency with Australian Therapeutic Guidelines ${ }^{10}$ treatment recommendations for each indication on the basis of the type, dose and frequency of antimicrobial prescribed. Duration of treatment was not included in the final analysis because, while EMR data included the total number of doses prescribed and repeat prescriptions, it did not include prescription instructions inputted as 'free text' by clinicians, which may have specified a duration of treatment.

Results of the analysis were reviewed by the authors and analysed for clinical insights relating to the choice of antimicrobial treatment for each of the three indications, which were relevant for consideration by GPs in their everyday practice. Ethics approval was received from the University of Melbourne Human Research Ethics Committee (1852745.3) and access to data from the Patron Database was approved by the University of Melbourne's Data for Decisions Data Governance Committee.

Generalisability of this analysis was limited by several factors. Antibiotics prescribed without a 'reason for prescription' or 'reason for visit' could not be directly linked to a condition for analysis, resulting in a smaller sample size. Only Therapeutic Guidelines was considered when determining appropriateness of antibiotic choice, meaning that other guidelines clinicians may have used were not considered. Data were not linked to medication dispensing to determine if scripts were filled, meaning delayed prescribing could not be analysed. Extracted data did not include culture results or identify follow-up reviews for the same indication, resulting in appropriate widening of an antibiotic spectrum. Finally, data not stored on the EMR used by clinicians in their decision-making process could not be considered. Despite these inherent limitations, various clinical insights were gained.

\section{Clinical insights}

\section{Sub-therapeutic dosing in acute otitis media in children}

Prescriptions for amoxicillin for AOM in children were frequently for a dose lower than recommended by Therapeutic Guidelines. ${ }^{10}$ Therapeutic Guidelines recommendations are shown in Table $1 .{ }^{11}$

Of the 238 prescriptions for AOM in children under 12 years of age, 156 prescriptions could be analysed for dose on the basis of the recorded weight of the child within six months of the prescription (the remaining prescriptions could not be analysed because no dose was recorded [24 prescriptions], no weight was recorded [24 prescriptions] or because the medication prescribed was not indicated under Therapeutic Guidelines [34 prescriptions]). Of the
Table 1. Therapeutic Guidelines recommendations for antibiotic regimens for acute otitis media"1

\begin{tabular}{|c|c|}
\hline \multirow[t]{3}{*}{ First-line recommendation } & $\begin{array}{l}\text { Amoxicillin } 15 \mathrm{mg} / \mathrm{kg} \text { up to } 500 \mathrm{mg} \text { orally, eight-hourly } \\
\text { for five days }\end{array}$ \\
\hline & OR \\
\hline & $\begin{array}{l}\text { Amoxicillin } 30 \mathrm{mg} / \mathrm{kg} \text { up to } 1000 \mathrm{mg} \text { 12-hourly for } \\
\text { five days }\end{array}$ \\
\hline \multirow[t]{2}{*}{$\begin{array}{l}\text { Delayed non-severe } \\
\text { hypersensitivity to penicillins }\end{array}$} & $\begin{array}{l}\text { First line: Cefuroxime (child aged } \geq 3 \text { months) } 15 \mathrm{mg} / \mathrm{kg} \\
\text { up to } 500 \mathrm{mg} 12 \text {-hourly for five days }\end{array}$ \\
\hline & $\begin{array}{l}\text { Second line: Trimethoprim + sulfamethoxazole (child } \\
\text { aged } \geq 1 \text { month) } 4+20 \mathrm{mg} / \mathrm{kg} \text { up to } 160+800 \mathrm{mg} \\
\text { orally } 12 \text { hourly for five days }\end{array}$ \\
\hline $\begin{array}{l}\text { Immediate hypersensitivity or } \\
\text { delayed severe hypersensitivity } \\
\text { to penicillins }\end{array}$ & $\begin{array}{l}\text { Trimethoprim + sulfamethoxazole (child } \geq 1 \text { month) } \\
4+20 \mathrm{mg} / \mathrm{kg} \text { up to } 160+800 \mathrm{mg} \text { orally } 12 \text {-hourly for } \\
\text { five days }\end{array}$ \\
\hline
\end{tabular}


156 prescriptions analysed, 151 were for amoxicillin and five were for cefuroxime. Of the 151 amoxicillin prescriptions, 58 (38\%) were for doses at least $25 \%$ below the recommended dose in Therapeutic Guidelines based on the child's recorded weight, seven (5\%) were for doses at least $25 \%$ greater than the recommend dose, and the remaining 86 prescriptions (57\%) were within $25 \%$ of the recommended dose.

Subtherapeutic dosing of antibiotics for AOM can lead to treatment failure ${ }^{12}$ and contribute to antimicrobial resistance. ${ }^{13}$ This is not unique to primary care. When compared with weight-based guideline recommendations, frequent subtherapeutic dosing of antibiotics, particularly amoxicillin, for AOM in children has been found in international studies in outpatient paediatric clinic ${ }^{13}$ and emergency department ${ }^{14}$ settings. This can be due to clinicians not referring to current guidelines, prescriber error and prescriber discomfort in using recommended high-dose amoxicillin regimens. ${ }^{14}$ Further research is required regarding antibiotic prescribing for children with AOM in primary care; however, targeted education, access to Therapeutic Guidelines ${ }^{15}$ and clinical decision support tools embedded in practice software prompting prescribers to weigh children and select an appropriate dosing regimen may promote optimal dosing for AOM in children.

\section{Antibiotic prescribing for tonsillitis and pharyngitis in adults}

Antibiotic prescriptions for tonsillitis and pharyngitis in adults were frequently not written in accordance with Therapeutic Guidelines recommendations (Table 2).

\section{Table 2. Therapeutic Guidelines recommendations for antibiotic regimens for acute tonsillitis and pharyngitis in adults ${ }^{16}$}

\section{First-line recommendation}

1) Phenoxymethylpenicillin $500 \mathrm{mg}$ orally, 12-hourly for 10 days

2) Benzathine benzylpenicillin 1.2 million units intramuscularly, as a single dose (used if patient adherence to the 10-day oral phenoxymethylpenicillin regimen is unlikely, oral therapy is not tolerated or a single-dose treatment is preferred)

\section{Delayed non-severe hypersensitivity to penicillins}

Immediate hypersensitivity or delayed severe hypersensitivity to penicillins
Azithromycin $500 \mathrm{mg}$ orally, daily for five days

Table 3. Antibiotics prescribed for tonsillitis and pharyngitis in adults

\begin{tabular}{|c|c|c|c|}
\hline & Medication name & $\begin{array}{r}\text { Number of } \\
\text { scripts }\end{array}$ & $\begin{array}{r}\text { Percentage of } \\
\text { total scripts }\end{array}$ \\
\hline \multirow{3}{*}{$\begin{array}{l}\text { Therapeutic } \\
\text { Guidelines } \\
\text { recommended } \\
\text { antibiotics }\end{array}$} & Phenoxymethylpenicillin & 399 & $50.2 \%$ \\
\hline & Cefalexin & 38 & $4.8 \%$ \\
\hline & Benzathine penicillin & 2 & $<1 \%$ \\
\hline \multirow{4}{*}{$\begin{array}{l}\text { Antibiotics not } \\
\text { recommended } \\
\text { by Therapeutic } \\
\text { Guidelines }\end{array}$} & Amoxicillin & 182 & $22.9 \%$ \\
\hline & Amoxicillin/clavulanic acid & 49 & $6.2 \%$ \\
\hline & Clarithromycin & 29 & $3.6 \%$ \\
\hline & Other & 96 & $12.3 \%$ \\
\hline Total & & 795 & $100 \%$ \\
\hline
\end{tabular}

Antibiotics are only indicated in populations at increased risk of complications or when symptoms are severe; ${ }^{16}$ it was not possible to reliably ascertain this from the data available and the authors assumed that these criteria were met for the purposes of analysis.

Antibiotic prescriptions for tonsillitis and pharyngitis in adults are summarised in Table 3. The most commonly prescribed antibiotic, phenoxymethylpenicillin, is recommended in Therapeutic Guidelines; the next two most common antibiotics prescribed, amoxicillin and amoxicillin/ clavulanic acid, are not. This is of particular relevance because studies have shown no difference in efficacy between broader-spectrum antibiotics and narrowspectrum phenoxymethylpenicillin in the treatment of acute tonsillitis and pharyngitis due to group A $\beta$-haemolytic streptococcus. ${ }^{17}$ Therefore, in order to reduce the risks of antimicrobial resistance, phenoxymethylpenicillin should be considered the first choice in the absence of penicillin allergy.

When phenoxymethylpenicillin was prescribed, the dose and frequency was consistent with Therapeutic Guidelines recommendations (500 $\mathrm{mg}$ twice daily) only $34 \%$ of the time. Doses were frequently for amounts $(1000 \mathrm{mg}$ twice daily in $21 \%$ of prescriptions) or frequencies (500 mg four times per day in $29 \%$ of prescriptions) greater than recommended.

Numerous factors may account for these findings. Firstly, guidelines for treatment of acute pharyngitis and tonsillitis vary considerably between countries. While amoxicillin is not recommended in Therapeutic Guidelines because of its broad spectrum and the risk of rash, amoxicillin is an alternative to phenoxymethylpenicillin in the Infectious Diseases Society of America (IDSA) guidelines. ${ }^{17}$ Similarly, clarithromycin is not recommended in Therapeutic Guidelines but is endorsed for penicillin allergy in the UK's National Institute for Health and Care Excellence (NICE) guidelines ${ }^{18}$ and IDSA guidelines. ${ }^{17}$ Further, Therapeutic Guidelines recommends a phenoxymethylpenicillin dosage of $500 \mathrm{mg}$ twice daily for 10 days, whereas the NICE guidelines 
recommend $500 \mathrm{mg}$ four times per day or $1000 \mathrm{mg}$ twice daily for 5-10 days. Access to Therapeutic Guidelines is via paid subscription, whereas the NICE guidelines and the IDSA guidelines are freely available online. Australian GPs may be referring to freely available international guidelines in their prescribing for tonsillitis and pharyngitis, again highlighting the importance of access to local guidelines.

\section{Acute rhinosinusitis in adults}

Acute rhinosinusitis in adults accounted for almost $5 \%$ of total prescriptions analysed (893 of 19,742 prescriptions); antibiotic prescriptions for this condition are summarised in Table 4.

Treatment of acute rhinosinusitis is primarily symptomatic therapy. The vast majority of acute sinusitis cases are viral, and antibiotics are not indicated. ${ }^{19}$ For acute bacterial rhinosinusitis, a clinical diagnosis making up just $2 \%$ of acute rhinosinusitis cases, antibiotics may be considered; however, shared decision making is recommended to discuss the benefits versus risks of therapy given antibiotics have not been shown to reduce severe complications or the total duration of symptoms. ${ }^{20}$

Australian data suggest that doctors prescribe antibiotics in approximately $41 \%$ of presentations with acute rhinosinusitis when only $0.5-8 \%$ of cases are estimated to benefit from antibiotics. ${ }^{21}$ Internationally it has been shown that up to $80 \%$ of patients presenting to primary care with acute rhinosinusitis in Denmark, Sweden, Spain, Argentina, Russia, Lithuania and Argentina receive antibiotics, with $68 \%$ of antibiotic prescriptions not following local guidelines. ${ }^{22}$

Clinical decision support tools embedded in practice software may improve prescribing practices for acute rhinosinusitis. A 2018 primary care study in New York City examined the impact of a 'best practice alert', which reminded prescribing doctors that over $90 \%$ of cases of acute sinusitis are viral and provided a link to guideline recommendations. ${ }^{23}$ This alert resulted in a $31 \%$ reduction in antibiotic prescribing for acute sinusitis over 12 months.

\section{Conclusion}

With increased access to primary care data, it will be possible to gain further insights into prescribing practices in the Australian setting. Although clinical context should always be considered, large EMR datasets provide exciting opportunities to assist GPs to reflect on and optimise their antimicrobial prescribing practices. Disseminating

\section{Table 4. Antibiotics prescribed for acute rhinosinusitis in adults}

\begin{tabular}{|c|c|c|c|}
\hline & Medication name & $\begin{array}{r}\text { Number of } \\
\text { scripts }\end{array}$ & $\begin{array}{r}\text { Percentage of } \\
\text { total scripts }\end{array}$ \\
\hline \multirow{5}{*}{$\begin{array}{l}\text { Therapeutic } \\
\text { Guidelines } \\
\text { recommended } \\
\text { antibiotics }\end{array}$} & Amoxicillin & 361 & $40.4 \%$ \\
\hline & Amoxicillin/clavulanic acid & 221 & $24.7 \%$ \\
\hline & Doxycycline & 131 & $14.7 \%$ \\
\hline & Cefuroxime & 24 & $2.7 \%$ \\
\hline & Trimethoprim + sulfamethoxazole & 5 & $0.6 \%$ \\
\hline \multirow{5}{*}{$\begin{array}{l}\text { Antibiotics not } \\
\text { recommended } \\
\text { by Therapeutic } \\
\text { Guidelines }\end{array}$} & Cefalexin & 40 & $4.5 \%$ \\
\hline & Clarithromycin & 35 & $3.9 \%$ \\
\hline & Roxithromycin & 33 & $3.7 \%$ \\
\hline & Cefaclor & 18 & $2.0 \%$ \\
\hline & Other & 25 & $2.8 \%$ \\
\hline Total & & 893 & $100 \%$ \\
\hline
\end{tabular}

information from primary care data on antimicrobial prescribing is especially important as there is currently no ongoing antimicrobial stewardship program in this setting. The analysis of EMR data to investigate prescribing practices provides the opportunity to improve patient care, uncover potential key underlying drivers of inappropriate antimicrobial prescribing choices and facilitate quality improvement.

\section{Authors}

Tim Monaghan MBBS, LLB (Hons), BComm, FRACGP, Clinical Informatician, Department of General Practice, Melbourne Medical School, Faculty of Medicine, Dentistry and Health Science, University of Melbourne, Melbourne, Vic

Ruby Biezen BSc, MAppSc, PhD, Research Fellow Infection and Immunisation Lead, Department of General Practice, Melbourne Medical School, Faculty of Medicine, Dentistry and Health Science, University of Melbourne, Melbourne, Vic

Kirsty Buising MBBS, MD, MPH, FRACP, Deputy Director, National Centre for Antimicrobial

Stewardship, University of Melbourne and Peter Doherty Institute for Infection and Immunity, Melbourne, Vic; Infectious Diseases Physician, Victorian Infectious Diseases Service, Royal Melbourne Hospital, Melbourne, Vic

Christine Hallinan PhD, MPH, BAppSc. Research Fellow - Biostatistics and Pharmacovigilance, Department of General Practice, Melbourne Medical School, Faculty of Medicine, Dentistry \& Health Science, University of Melbourne, Melbourne, Vic

Ron Cheah BPharm, GradCertPharmPrac, MPharmPrac, Project Officer, National Centre for Antimicrobial Stewardship, Peter Doherty Institute for Infection and Immunity, Melbourne, Vic; Pharmacy Department, Monash Health, Melbourne, Vic

Jo-Anne Manski-Nankervis BSc (Hons), MBBS (Hons), CHIA, PhD, FRACGP, Associate Professor, Department of General Practice, Melbourne Medical School, Faculty of Medicine, Dentistry and Health Science, University of Melbourne, Melbourne, Vic Competing interests: The authors have previously received funding from the Therapeutic Guidelines Limited (TGL)/The Royal Australian College of General Practitioners Foundation Research Grant (2017 and 2019), and TGL provided subscriptions to general practice participants in those studies. JM was supported by a Medical Research Future Fund Next Generation Clinician Researcher Translating Research into Practice Fellowship.

Funding: None.

Provenance and peer review: Not commissioned, externally peer reviewed.

Correspondence to:

tim.monaghan@unimelb.edu.au

\section{Acknowledgements}

This research used de-identified patient data from the Patron primary care data repository (extracted from consenting general practices), which has been created and is operated by the Department of General Practice, University of Melbourne (www.gp.unimelb.edu.au/datafordecisions). 


\section{References}

1. Shehab N, Patel PR, Srinivasan A, Budnitz DS. Emergency department visits for antibioticassociated adverse events. Clin Infect Dis 2008;47(6):735-43. doi: 10.1086/591126.

2. Kuscu F, Ulu A, Inal AS, et al. Potential drug-drug interactions with antimicrobials in hospitalized patients: A multicenter point-prevalence study. Med Sci Monit 2018;24:4240-47. doi: 10.12659/ MSM.908589.

3. Australian Commission on Safety and Quality in Health Care. Antimicrobial medicines dispensing from 2013-14 to 2017-18. Sydney, NSW: ACSQHC, 2020.

4. Australian Commission on Safety and Quality in Health Care. AURA 2019: Third Australian report on antimicrobial use and resistance in human health. Sydney, NSW: ACSQHC, 2019.

5. Australian Commission on Safety and Quality in Health Care. AURA 2019 - Areas for action: 2019-2020. Sydney, NSW: ACSQHC, 2019.

6. Busingye D, Gianacas C, Pollack A, et al. Data resource profile: Medicinelnsight, an Australian national primary health care database. Int J Epidemiol 2019;48(6):1741-41h. doi: 10.1093/ije/ dyz147.

7. Department of General Practice, University of Melbourne. Data for Decisions and the Patron program of research [Internet]. Melbourne, Vic: Department of General Practice, University of Melbourne, 2018. Available at https://medicine. unimelb.edu.au/school-structure/generalpractice/engagement/data-for-decisions [Accessed 7 June 2021].

8. Outcome Health. POpulation Level Analysis and Reporting (POLAR) GP/POLAR Explorer. Blackburn East, Vic: Outcome Health, 2019.

9. Australian Institute of Health and Welfare. Primary health care data development. Canberra, ACT: AlHW, 2021.

10. Therapeutic Guidelines Limited. eTG complete. West Melbourne, Vic: Therapeutic Guidelines Limited, 2021.

11. Expert Group for Antibiotic. Otitis media. In: eTG complete. West Melbourne, Vic: Therapeutic Guidelines Limited, 2019.

12. Pichichero ME, Reed MD. Variations in amoxicillin pharmacokinetic/pharmacodynamic parameters may explain treatment failures in acute otitis media. Paediatr Drugs 2009:11(4):243-49. doi: 10.2165/00148581-200911040-00003

13. Garbutt J, Jeffe DB, Shackelford P. Diagnosis and treatment of acute otitis media: An assessment. Pediatrics 2003;112(1 Pt 1):143-49. doi: 10.1542/ peds.112.1.143.

14. Barstow L, Herman E, Phillips H, Maloney P. Assessment of emergency department antibiotic discharge prescription dosing errors for pediatric patients in a community hospital health system. Pediatr Emerg Care 2020;36(7):e393-96. doi: 10.1097/ PEC.0000000000001458.

15. Neels AJ, Bloch AE, Gwini SM, Athan E. The effectiveness of a simple antimicrobial stewardship intervention in general practice in Australia: A pilot study. BMC Infect Dis 2020;20(1):586. doi: 10.1186/s12879-020-05309-8.

16. Expert Group for Antibiotic. Sore throat. In: eTG complete. West Melbourne, Vic: Therapeutic Guidelines Limited, 2019

17. Shulman ST, Bisno AL, Clegg HW, et al. Clinical practice guideline for the diagnosis and management of group A streptococcal pharyngitis: 2012 update by the Infectious Diseases Society of America. Clin Infect Dis 2012;55(10):e86-102. doi: 10.1093/cid/cis629.

18. The National Institute for Health and Care Excellence. Sore throat (acute): Antimicrobia prescribing. NG84. London, UK: NICE, 2020. Available at www.nice.org.uk/guidance/ng84 [Accessed 16 April 2021].

19. Jaume F, Valls-Mateus M, Mullol J. Common cold and acute rhinosinusitis: Up-to-date management in 2020. Curr Allergy Asthma Rep 2020;20(7):28. doi: 10.1007/s11882-020-00917-5.

20. Expert Group for Antibiotic. Acute rhinosinusitis In: eTG complete. West Melbourne, Vic: Therapeutic Guidelines Limited, 2019.

21. McCullough AR, Pollack AJ, Plejdrup Hansen M, et al. Antibiotics for acute respiratory infections in general practice: Comparison of prescribing rates with guideline recommendations. Med J Aust 2017;207(2):65-69. doi: 10.5694/mja16.01042.

22. Jørgensen LC, Friis Christensen $S$, Cordoba Currea G, Llor C, Bjerrum L. Antibiotic prescribing in patients with acute rhinosinusitis is not in agreement with European recommendations. Scand J Prim Health Care 2013;31(2):101-05. doi: 10.3109/02813432.2013.788270.

23. Ginzburg R, Conway JJ, Waltermaurer E, Song W, Jellinek-Cohen SP. Using clinical decision support within the electronic health record to reduce incorrect prescribing for acute sinusitis. J Patient Cent Res Rev 2018:5(3):196-203. doi: 10.17294/2330-0698.1619. 